\title{
Cell Stress Proteins in Atherothrombosis
}

\author{
Julio Madrigal-Matute, Roxana Martinez-Pinna, \\ Carlos Ernesto Fernandez-Garcia, Priscila Ramos-Mozo, Elena Burillo, \\ Jesus Egido, Luis Miguel Blanco-Colio, and Jose Luis Martin-Ventura
}

\author{
Vascular Research Laboratory, IIS-Fundación Jiménez Díaz, Universidad Autónoma de Madrid, 28040 Madrid, Spain \\ Correspondence should be addressed to Julio Madrigal-Matute, jmadrigal@fjd.es
}

Received 30 March 2012; Accepted 14 May 2012

Academic Editor: Ana Fortuno

Copyright (C) 2012 Julio Madrigal-Matute et al. This is an open access article distributed under the Creative Commons Attribution License, which permits unrestricted use, distribution, and reproduction in any medium, provided the original work is properly cited.

Cell stress proteins (CSPs) are a large and heterogenous family of proteins, sharing two main characteristics: their levels and/or location are modified under stress and most of them can exert a chaperon function inside the cells. Nonetheless, they are also involved in the modulation of several mechanisms, both at the intracellular and the extracellular compartments. There are more than 100 proteins belonging to the CSPs family, among them the thioredoxin (TRX) system, which is the focus of the present paper. TRX system is composed of several proteins such as TRX and peroxiredoxin (PRDX), two thiol-containing enzymes that are key players in redox homeostasis due to their ability to scavenge potential harmful reactive oxygen species. In addition to their main role as antioxidants, recent data highlights their function in several processes such as cell signalling, immune inflammatory responses, or apoptosis, all of them key mechanisms involved in atherothrombosis. Moreover, since TRX and PRDX are present in the pathological vascular wall and can be secreted under prooxidative conditions to the circulation, several studies have addressed their role as diagnostic, prognostic, and therapeutic biomarkers of cardiovascular diseases (CVDs).

\section{Introduction}

The vast majority of the proteins require further assistance for acquiring proper maturation and stability; this process described in the late $80 \mathrm{~s}$ is facilitated through the activity of a family of proteins called "molecular chaperones" or cell stress proteins (CSPs) [1]. This large and diverse group of proteins composed by more than 20 families of proteins and more than 100 proteins includes the heat shock proteins (HSPs) and the thioredoxin (TRX) system. The role of HSPs in cardiovascular diseases (CVDs) has been thoroughly reviewed [2]. In the present paper, we will focus on the role of the TRX system, specifically TRX and peroxiredoxins (PRDXs), in atherothrombosis. For this purpose, we have followed the PRISMA chart displayed in Supplementary Figure 1 (see Suppplementary Figure 1 in supplementary material available online at doi:10.1155/2012/232464).

\section{The Thioredoxin System}

The TRX system mainly comprises TRX, TRX reductase, TRX interacting protein ((TXNIP), vitamin D3-upregulated protein-1 ((VDUP)-1) or TRX-binding protein (TRXBP)), and the PRDXs [3]. The TRX system is involved in protein assembly and plays a key role in cellular redox maintenance.

Under physiological conditions, intra- and extracellular reactive oxygen species (ROS) modulate metabolic, signaling, and transcriptional processes within the cell. However, pathological dysregulation of the redox balance could contribute to CVDs $[4,5]$. Cellular redox homeostasis is tightly regulated by the coordinated action of NADPH oxidases, the TRX system and glutathione (GSH) [6], among others. The TRX system and GSH are thiol reduction systems with a key role in the defense against excessive ROS production, as well as in the modulation of signaling processes such as inflammation, cellular proliferation, and apoptosis [7-9]. These molecules maintain the intracellular milieu in a reduced state. GSH is used by the GSH peroxidase to reduce peroxides, producing oxidized GSH (GSSG) while GSH reductase reduces this oxidized form to GSH. The antioxidant properties of TRX result from PRDX action, which recycle $\mathrm{H}_{2} \mathrm{O}_{2}$ through reduction of several hydroperoxides into water and alcohol (Figure 1). 


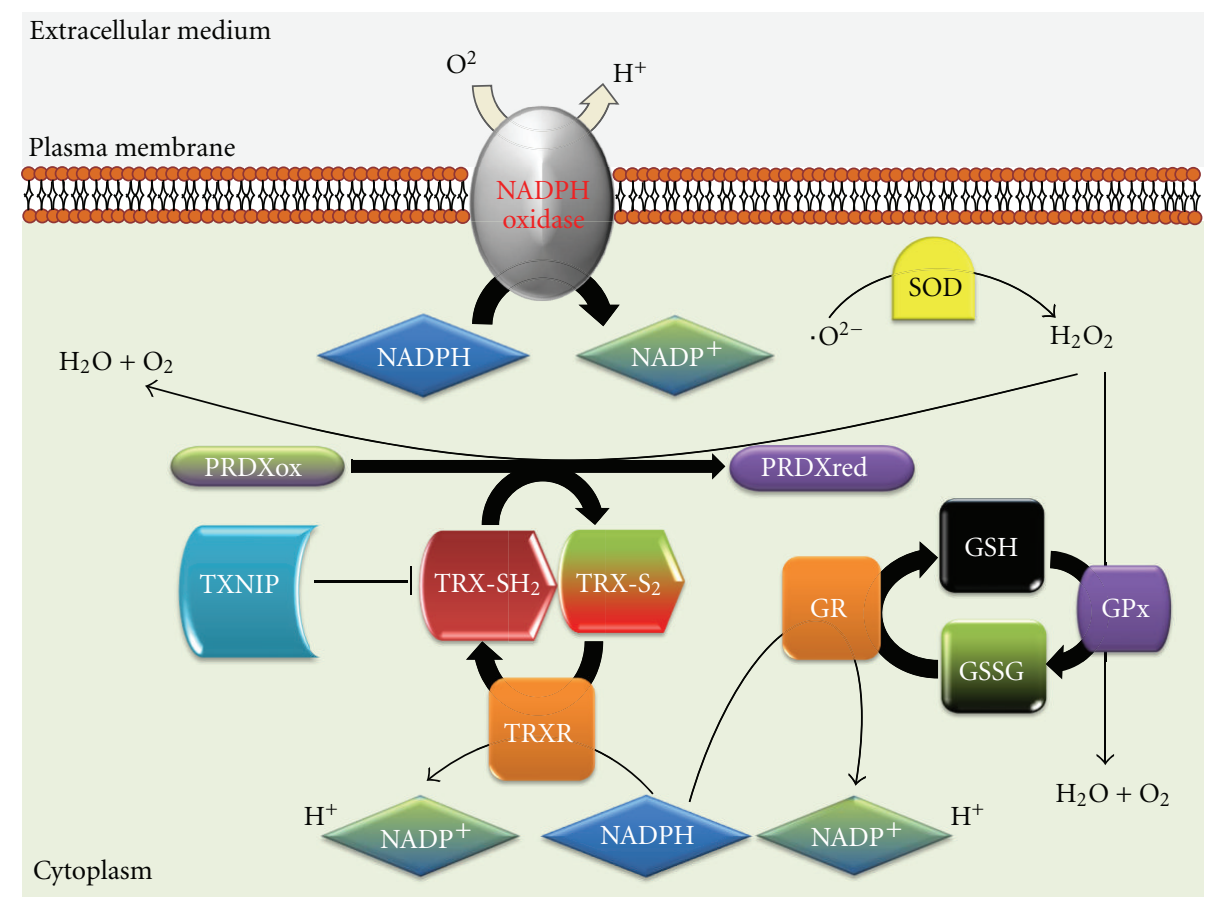

FIGURE 1: Schematic diagram showing the maintenance of the cellular redox homeostasis by the NADPH oxidase, GSH, and the TRX

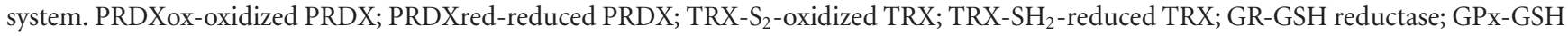
peroxidase.

Depending on their cellular location, TRX/PRDX may exert different functions than their known chaperone and antioxidant activities. This process can be described with the so-called "Moonlighting proteins" theory [10]. This idea supports the notion that one gene $=$ one protein $=$ one function is simple and old-fashioned because large number of proteins have two or more functions. This theory might not apply to every protein but it seems to be right for TRX/PRDX. Under certain circumstances, mainly prooxidative conditions, TRX and PRDX could be released to the extracellular milieu $[11,12]$ although their trafficking mechanisms are not yet fully described.

2.1. Intracellular TRX. TRXs are a class of small redox molecules $(\sim 12 \mathrm{kDa})$ present in prokaryotes and eukaryotes and are essential for cellular viability [13]. So far, 3 human TRX variants have been characterized codified by different genes. TRX1 is localized under resting conditions in the cytosol but can be translocated upon stress conditions [14] (e.g., it can be found in an oxidized form in the nucleus of exponential growing cells [15] (Figure 2)), TRX2 is mitochondrial $[16,17]$, and SpTRX [18] is abundantly expressed in spermatozoa. TRX has a redox active disulfide/dithiol site within 2 conserved Cys residues [19], and it functions as an antioxidant molecule by protecting cells against $\mathrm{H}_{2} \mathrm{O}_{2}$ [20], regulating heme-oxygenase 1 (HO-1) expression [21], or inducing manganese superoxide dismutase (MnSOD) in the mitochondria [22]. Moreover, it has a protective role against nitric-oxide- (NO-) induced stress, regulating $\mathrm{NO}$ synthases activity [23] and through other NO regulating processes [24]. In addition to its role as antioxidant protein, TRX interacts with numerous signaling molecules (including apoptosis signal-regulating kinase 1 (ASK1) and TXNIP) and transcription factors such as nuclear factor-kappa $\mathrm{B}$ $(\mathrm{NF}-\kappa \mathrm{B})$ and activating protein 1 (AP-1). TRX function can be regulated by redox modification (e.g., NO increases Snitrosylation of TRX stimulating TRX activity [25]) or by TXNIP binding [26] (reducing TRX activity), among other mechanisms.

Regarding intracellular TRX in vivo functions, as TRX$1 \mathrm{KO}$ mice are lethal, some information has been obtained from studies performed in TRX transgenic (Tg) mice [27]. TRX overexpression in mice protects placenta from oxidative stress and fetal growth by augmenting glucose availability [28], and it also functions as a shelter against apoptosis induced by extensive oxidation in diabetic embryopathy [29] or streptozotocin-induced diabetic osteopenia [30]. Furthermore, TRX is able to protect the lung injury provoked by diesel exhaust particles (DEPs) derived from diesel engine-powered automobiles and industrial machines. This protective role, played through AKT modulation, is reflected in the augmented TRX levels in control cells induced by DEP [31]. Also, mediated by AKT signaling, TRX protects neurons against apoptosis during brain focal ischemia [32].

Thus, the major role of TRX in the redox balance is supported by the numerous data regarding the protection exerted by TRX against excessive oxidative damage in different diseases and the embryonic lethality of KO mice for TRX.

2.2. Intracellular PRDX. PRDXs are a recent discovery among the peroxidases lacking the hemo group. PRDX protein levels are very abundant, around $0.1-1 \%$ of total soluble protein in mammals, and they are ubiquitously distributed in all organisms $[12,33]$. PRDXs are thiol-specific enzymes 


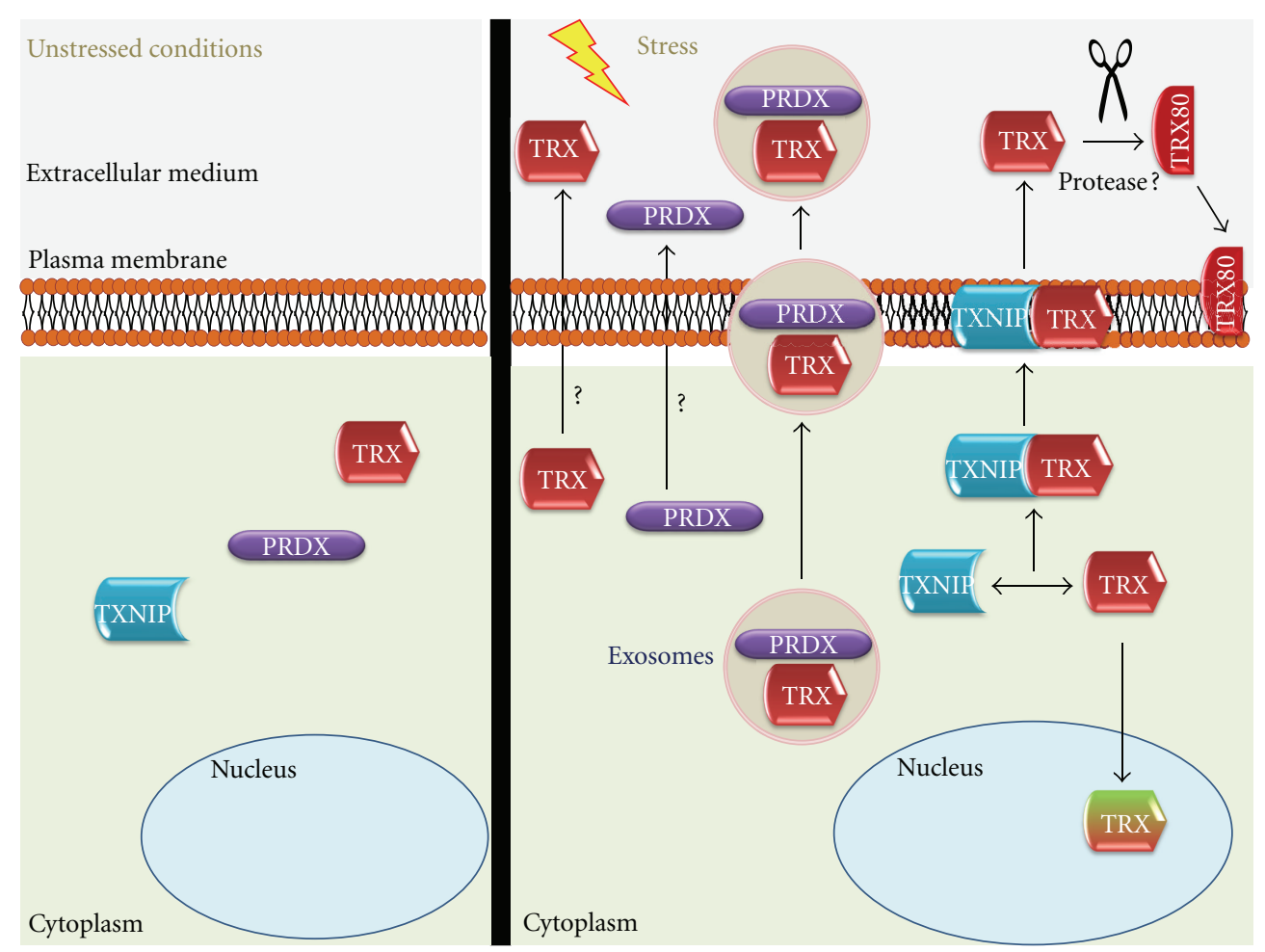

FIGURE 2: Schematic diagram showing PRDX1/TRX main cellular location under nonstress conditions (left), under oxidative stress (right) and trafficking mechanisms (right).

lacking selenium, and they use their active sites to reduce peroxides and scavenge ROS [12]. Mammal cells express 6 PRDX isoforms (PRDX 1-6): 1, 2, and 6 are cytosolic, and 3 and 5 are mitochondrial, while 4 is described as a secretory protein in most tissues [34]. Every isoform contains a conserved Cys residue, which is the primary site for $\mathrm{H}_{2} \mathrm{O}_{2}$ oxidation, and they can be further classified according to their Cys residues (PRDX1-4 belongs to the 2-Cys subfamily, PRDX5 or atypical 2-Cys and PRDX6 or 1-Cys PRDX) [35].

PRDXs scavenge $\mathrm{H}_{2} \mathrm{O}_{2}$ more efficiently than other systems such as catalase due to its higher affinity for $\mathrm{H}_{2} \mathrm{O}_{2}$ [36]. PRDX can modulate NADPH oxidase activity through $\mathrm{H}_{2} \mathrm{O}_{2}$ inactivation [37]. In addition, PRDX can also reduce peroxynitrites levels through peroxynitrites reductases [38]. Among the mechanisms modifying PRDX functions, several posttranslational modifications have been described, such as nitrosylation [39], glutathionylation [40], phosphorylation, and the hyperoxidation of its active site [41], which stimulates its chaperone activity [42]. For example, under low $\mathrm{H}_{2} \mathrm{O}_{2}$ concentrations produced in conditions of cellular homeostasis PRDX forms low-molecular-weight oligomers, exerting peroxidase activity. However, under significant changes in $\mathrm{H}_{2} \mathrm{O}_{2}$ concentration, PRDX experiences structural changes and forms high-molecular-weight oligomers and acquires chaperone activity $[43,44]$. Similarly to TRX, PRDX interacts with several proteins (e.g., cyclophilin A, macrophage inhibitory factor, etc.) and can modulate the function of these binding proteins, in a dependent or independent manner of the PRX redox status [35].

Mice lacking PRDX1 are viable with a phenotype characterized by hemolytic anemia caused by an increased ROS production by red blood cells (RBCs). Furthermore, PRDX1 has tumor suppressor properties as PRDX1 KO mice show an increased rate in malignant tumors as they age, which can be explained by the excessive accumulation of damaged tissue due to extreme ROS production [45]. Similarly to PRDX1 $\mathrm{KO}$ mice, targeted disruption of PRDX2 causes cysteine oxidation of several proteins on RBCs membranes, which finally results in augmented levels of denatured protein, cell toxification, and hemolysis [46]. PRDX2 also has been identified as a tumor suppressor gene [47]. Accordingly, PRDX3 (also known as MER5) KO mice are characterized by increased ROS production in macrophages and develop more severe lung injury upon Lipopolisaccharide (LPS) induction, possibly due to an excessive DNA and protein oxidative damage and inflammatory cell infiltration [48]. In fact, it has been calculated that almost $90 \%$ of $\mathrm{H}_{2} \mathrm{O}_{2}$ targets PRDX3 within the mitochondrial matrix, playing a major role in redox signaling in the mitochondria [49], protecting the cells against apoptosis induced by excessive damage to mitochondrial macromolecules [50]. PRDX3 absence is also involved in mitochondrial dysregulation associated with obesity, through increased protein carbonylation and ROS production [51]. It is noteworthy that PRDX3 KO adipocytes accumulate more fat than wild type due to hypertrophy and defects in the levels of enzymes implicated in glucose/lipid metabolism [51]. PRDX4 is mostly a secretory protein, while it is attached to the endoplasmic reticulum (ER) membrane of spermatogenic cells in mature testes. In these cells PRDX4 protects from cell death through its antioxidant properties, nonetheless PRDX4 KO spermatozoa shows normal fertilization [52]. To our knowledge there is no PRDX5 KO strain, 
although it has been described that PRDX5 overexpression prevents ROS production and p53-dependent apoptosis [53]. Nevertheless, KO mice for PRDX6, the only 1-Cys member of the peroxiredoxin family, were more vulnerable to ischemic reperfusion injury as shown by increased infarct size and higher amount oxidative stress [54]. In agreement, PRDX6 overexpression functions as a shelter in mouse lungs against toxicity of hyperoxia [55].

On the whole, the plethora of data regarding the different isoforms of PRDX demonstrate that every subunit, independently of its location, is a member of one of the major cellular systems in charge of scavenging prooxidant species and thus in the maintenance of cellular redox status.

2.3. Extracellular TRX. TRX expression can be augmented very fast under stress and is secreted by normal and tumor cells although its secretion does not seem to follow a classical Golgi apparatus pathway [11]. TRX location is regulated by TXNIP binding [26] and facilitates TRX transport from cytoplasm to the membrane under oxidative stress [14]. Another mechanism that can be involved in TRX active secretion is the exosomal pathway. Exosomes are small microparticles released by cells upon activation or apoptosis. These vesicles have been implicated in thrombosis, diabetes, inflammation, atherosclerosis, and vascular cell proliferation [56]. Proteomic studies have described the presence of TRX in exosomes in B cells [57], bladder cancer cells [58], colorectal cancer cells [59], and urine [60] (Figure 2).

There is also a truncated form of TRX that corresponds to the last $80-84$ amino acids from the N-terminal end, named TRX80, and it is present in plasma where it was firstly identified as a stimulating factor of eosinophils cytotoxicity [61]. It is possibly a result of protease activity but this process is still unknown (Figure 2). Recombinant TRX80 is a potent mitogenic cytokine for peripheral blood mononuclear cells (PBMCs), an effect not shared by TRX [62]. TRX80 differs from TRX because it forms a dimer lacking reductase activity and its activity is independent of the Cys residues from the TRX active site. The main cellular target for TRX80 are PBMCs in which it induces a Th1 response via IL12 production [63].

Extracellular TRX is present in the circulation and its levels are increased under oxidative stress or inflammation [64] (Figure 2). TRX has been pointed out as a biomarker in numerous oxidative and inflammatory diseases such as rheumatoid arthritis (RA) in which plasma TRX levels of normal subjects were significantly lower than those of RA patients and correlated with RA disease activity and Creactive protein [65]. TRX levels were increased in patients with systemic inflammatory stress syndrome (SIRS)/sepsis compared to control subjects [66].

2.4. Extracellular PRDX. PRDX1 can be found inside the Golgi apparatus on endothelial cells (ECs) [67], and under phorbol 12-myristate 13-acetate (PMA) stimulation PRDX1 is translocated to the cellular membrane [68], as also showed for PRDX6 in polymorphonuclear cells (PMNs) [69] (Figure 2). PRDX might also be secreted by lung cancer cells through a nonclassical pathway $[70,71]$. Nonetheless, the extracellular function of PRDX is still unknown. Unlike the well-described function of intracellular PRDX1, membrane PRDX6 helps in the maintenance of an optimal NADPH oxidase activity [69]. A number of chaperones, including TRX and HSPs, are released by stressed or dying cells, acting as an endogenous warning system through binding of these signals to receptors on the outer membrane [72-75]. Most of these signals are recognized by Toll-like receptor 4 (TLR4) [74, 75]. Accordingly, PRDX1 binds TLR4 and stimulates proinflammatory cytokine production in macrophages and dendritic cells, which suggests that PRDX could be acting as damage-associated molecular-pattern molecule (DAMP). Its trafficking seems to be dependent on PRDX binding to protein kinase $C$ (PKC) through microvesicles [76]. In fact, exosomes can be participating in active transport of PRDX since proteomic studies have described PRDX in exosomes in B cells [57], bladder cancer cells [58], breast cancer cells [77], breast milk [78], colorectal cancer cells [59], and saliva [79] (Figure 2).

Thus, it is tempting to speculate that extracellular levels of PRDX/TRX result from a cellular response to high oxidant conditions in the outer milieu.

\section{TRX/PRDX in Atherothrombosis}

Atherothrombosis is an immune-inflammatory disease, originated by the subendothelial accumulation of LDLs, that can be oxidized by ROS. Oxidative stress is involved not only in the first stages of atherogenesis by modifying LDLs or NO, but also in later stages of atherothrombosis by modulating the expression of proteases that weakens the fibrous cap $[80,81]$. ROS overproduction also produces direct damage to macromolecules such as lipids, nucleic acids, and proteins [82]. Furthermore, ROS can act as signaling molecules by inducing the activation of several cells from the vasculature. For example, through LDL oxydation and/or direct cell targeting, ROS can induce endothelial dysfunction and further leucocyte activation, deposition, and extravasation. In addition, ROS are clearly involved in the activation of vascular smooth muscle cells (VSMCs) from the lesion and sustain foam cell formation. Thus, pathological ROS overproduction is a main feature in atherogenesis and plaque rupture, which finally results in almost $70 \%$ of the clinical events [83].

Among the different systems involved in the redox maintenance in the vasculature, one of the most active is the TRX system. It is present in ECs $[14,84]$, VSMCs $[85,86]$, monocytes/macrophages [87, 88], RBCs [89, 90], and PMNs $[90,91]$. Since TRX and PRDX are present in the atherosclerotic plaque and they can modulate different mechanisms involved in CVDs, several studies have addressed their role as diagnostic, prognostic, and therapeutic biomarkers.

3.1. TRX. TRX is abundantly expressed in the vasculature, and its levels are increased under oxidative stress, possibly as a response mechanism to augmented ROS production [19]. Besides, TRX expression in the endothelium and 
in macrophages is augmented in atherosclerotic patients [92] and in arteries damaged by the balloon model [93]. More recently, TRX has been pointed as a possible marker for unstable atherosclerotic plaques due to its association with oxidative stress and intraplaque hemorrhage in culprit lesions [94]. TRX reductase is as well overexpressed in atherosclerotic plaques, maybe synthesized by macrophages engulfing oxLDLs [95].

The antioxidant effects of TRX are shown when overexpressed in mouse hearts, protecting them from myocardial infarction and displaying significantly improved postischemic ventricular recovery [96]. The positive effects of TRX in myocardial infarction are also due to its neoangiogenic properties as shown in different murine models [97, 98].

On the other hand, TRX can function as a signaling molecule by decreasing pressure-overload cardiac hypertrophy [99], maybe through upregulation of miR-98 [100]. However, there is a controversy about this matter because almost at the same time it was published another article in which the authors described that activation of TRX participates in the development of pressure-overload cardiac hypertrophy. In this respect, animals overexpressing TXNIP developed less hypertrophy [101]. Furthermore, transverse aortic constriction increased TRX activity accompanied by a $40 \%$ reduction in TXNIP levels [101]. Whether variations in TXNIP and TRX levels/activity reflect an increase in oxidative stress or they act as signaling molecules is still a matter to elucidate [102].

Recent studies have shown that extracellular TRX can inhibit interleukin-1 expression stimulated by LPS in monocyte-derived macrophages [103]. Besides, TRX1 administration has beneficial effects on myosin-induced autoimmune myocarditis through inhibition of inflammatory mediators and macrophage infiltration [104] and TRX1 also protects from reperfusion-induced arrhythmias [105]. Furthermore, TRX administration has been also shown to be beneficial in cerebral ischemia/reperfusion injury reducing the infarcted area through its antioxidant properties [106]. As an additional support for the beneficial effects of TRX in therapeutics, it is to note that TRX-1 gene delivery protects hypertensive rats from myocardial infarction through $\mathrm{HO}-$ 1/B-cell lymphoma 2 (BCL-2) [107].

Regarding cardiovascular diseases, TRX levels are elevated in plasma from atherothrombotic patients [108, 109], and high homocysteine plus low TRX is related to CAD severity [110]. Furthermore, TRX was elevated in patients following angioplasty, and there was an association with increased TRX levels and decreased rate of restenosis at follow-up angiography (6 months) [111]. We have recently reported an increase in serum TRX from abdominal aortic aneurysm (AAA) patients compared with control subjects. Besides, TRX correlates with AAA size and expansion rate which suggests that TRX could be a good biomarker of AAA evolution [91].

3.2. PRDX. PRDX expression can be modified by prooxidative stimulus such as LPS or the phorbol ester 12-O-tetradecanoylphorbol- 13 -acetate (TPA) [88, 112]. Attention to
PRDX as a major regulator of $\mathrm{H}_{2} \mathrm{O}_{2}$ homeostasis is growing [34]. In cells stimulated with platelet-derived growth factor (PDGF) or tumor necrosis factor alpha, PRDX overexpression or silencing provoked, respectively, reduction or increase of $\mathrm{H}_{2} \mathrm{O}_{2}$ levels [113]. Moreover, through $\mathrm{H}_{2} \mathrm{O}_{2}$ scavenging, PRDX can inhibit the NF- $\kappa \mathrm{B}$ pathway and consequently the inflammatory response [114]. Different PRDX isoforms seem to modulate different cellular responses. For example, transfection of VSMCs from rat pulmonary artery with an expression plasmid for PRDX1 increases proliferation rate significantly [115]. PRDX1 also diminishes leucocytes activation and adhesion to vascular endothelium. Double KO mice for PRDX1 and ApoE chow fed showed larger atherosclerotic lesions and macrophages enriched than ApoE KO mice [116]. KO mice for PRDX2/ApoE showed exacerbated atherosclerotic lesion formation dependent both on vascular and hematopoietic cells. Besides, immune cells accumulation in the atherosclerotic lesions is increased due to PRDX2 absence and also redox-dependent signaling PRDX2 [117]. Moreover, PRDX2 modulates PDGF signaling, inhibiting thereby cell proliferation and migration $[113,118]$. Using different in vivo models, it was shown that CD36 KO mice produce lower levels of ROS, along with an increase in heme-oxygenase $(\mathrm{HO}-1)$ and PRDX2. Furthermore, NF-E2-related factor-2 (Nrf2), a transcription factor in charge of the transcriptional regulation of HO-1 and PRDX2, knockdown led to increased ROS production and a prothrombotic phenotype under $\mathrm{FeCl}_{3}$ treatment, a similar phenotype to that of PRDX2 KO mice [119]. Regarding PRDX2 and vascular diseases, it has been recently shown that PRDX2 is overexpressed in ruptured AAA tissue compared with nonruptured [120]. This could be associated with the increased oxidative stress observed in AAA tissue, which produces 2.5 times higher superoxide than adjacent non-AAA tissue and 10 times higher than nonpathological aorta [121].

Besides, PRDX3 overexpression prevents ventricular remodeling and cardiac failure after myocardial infarction in mice [122]. As mentioned above, PRDX6 protects mice against ischemic reperfusion injury [54]. Although, little is known about circulating levels of PRDX, we have recently described high PRDX1 levels in serum from AAA patients [90]. Besides, PRDX1 levels correlated positively with size and expansion rate of AAA, suggesting its potential role as diagnostic and prognostic biomarker for AAA.

\section{Conclusion}

On the whole, we have summarized several findings that demonstrate the major role of the TRX system in the maintenance of the redox status in CVDs. Furthermore, the extracellular levels of PRDX/TRX seem to be related with a prooxidative scenario and there is growing data suggesting their potential role as biomarkers for oxidative-stress-related diseases. Finally, their value as useful therapeutic tools is being tested and future studies are necessary to validate thier prospective beneficial effects in CVDs. 


\section{Acknowledgments}

This work was supported by the Spanish Ministerio de Ciencia y Tecnología (SAF 2010-21852), Ministerio de Sanidad y Consumo, Instituto de Salud Carlos III, Redes RECAVA (RD06/0014/0035), Ministerio de Sanidad y Consumo, Instituto de Salud Carlos III (PI10/00072), and Sociedad Española de Arterosclerosis and Fundación Lilly.

\section{References}

[1] S. M. Hemmingsen, C. Woolford, S. M. Van der Vies et al., "Homologous plant and bacterial proteins chaperone oligomeric protein assembly," Nature, vol. 333, no. 6171, pp. 330-334, 1988.

[2] J. Madrigal-Matute, J. L. Martin-Ventura, L. M. BlancoColio, J. Egido, J. B. Michel, and O. Meilhac, "Heat-shock proteins in cardiovascular disease," Advances in Clinical Chemistry, vol. 54, pp. 1-43, 2011.

[3] G. Powis, M. Briehl, and J. Oblong, "Redox signalling and the control of cell growth and death," Pharmacology and Therapeutics, vol. 68, no. 1, pp. 149-173, 1995.

[4] R. Albertini, R. Moratti, and G. De Luca, "Oxidation of lowdensity lipoprotein in atherosclerosis from basic biochemistry to clinical studies," Current Molecular Medicine, vol. 2, no. 6, pp. 579-592, 2002.

[5] Y. Lavrovsky, B. Chatterjee, R. A. Clark, and A. K. Roy, "Role of redox-regulated transcription factors in inflammation, aging and age-related diseases," Experimental Gerontology, vol. 35, no. 5, pp. 521-532, 2000.

[6] C. J. World, H. Yamawaki, and B. C. Berk, "Thioredoxin in the cardiovascular system," Journal of Molecular Medicine, vol. 84, no. 12, pp. 997-1003, 2006.

[7] A. Holmgren, "Antioxidant function of thioredoxin and glutaredoxin systems," Antioxidants and Redox Signaling, vol. 2, no. 4, pp. 811-820, 2000.

[8] G. Powis and W. R. Montfort, "Properties and biological activities of thioredoxins," Annual Review of Biophysics \& Biomolecular Structure, vol. 30, pp. 421-455, 2001.

[9] Z. A. Wood, L. B. Poole, and P. A. Karplus, "Peroxiredoxin evolution and the regulation of hydrogen peroxide signaling," Science, vol. 300, no. 5619, pp. 650-653, 2003.

[10] C. J. Jeffery, "Moonlighting proteins," Trends in Biochemical Sciences, vol. 24, no. 1, pp. 8-11, 1999.

[11] A. Rubartelli, A. Bajetto, G. Allavena, E. Wollman, and R. Sitia, "Secretion of thioredoxin by normal and neoplastic cells through a leaderless secretory pathway," Journal of Biological Chemistry, vol. 267, no. 34, pp. 24161-24164, 1992.

[12] S. G. Rhee, H. Z. Chae, and K. Kim, "Peroxiredoxins: a historical overview and speculative preview of novel mechanisms and emerging concepts in cell signaling," Free Radical Biology and Medicine, vol. 38, no. 12, pp. 1543-1552, 2005.

[13] I. Slaby and A. Holmgren, "Thioredoxin reductase-dependent insulin disulfide reduction by phage T7 DNA polymerase reflects dissociation of the enzyme into subunits," Journal of Biological Chemistry, vol. 264, no. 28, pp. 16502-16506, 1989.

[14] C. World, O. N. Spindel, and B. C. Berk, "Thioredoxininteracting protein mediates TRX1 translocation to the plasma membrane in response to tumor necrosis factor$\alpha$ : a key mechanism for vascular endothelial growth factor receptor-2 transactivation by reactive oxygen species," Arteriosclerosis, Thrombosis, and Vascular Biology, vol. 31, no. 8, pp. 1890-1897, 2011.
[15] J. C. Spielberger, A. D. Moody, and W. H. Watson, "Oxidation and nuclear localization of thioredoxin-1 in sparse cell cultures," Journal of Cellular Biochemistry, vol. 104, no. 5, pp. 1879-1889, 2008.

[16] G. Spyrou, E. Enmark, A. Miranda-Vizuete, and J. A. Gustafsson, "Cloning and expression of a novel mammalian thioredoxin," Journal of Biological Chemistry, vol. 272, no. 5, pp. 2936-2941, 1997.

[17] T. Tanaka, F. Hosoi, Y. Yamaguchi-Iwai et al., "Thioredoxin2 (TRX-2) is an essential gene regulating mitochondria-dependent apoptosis," EMBO Journal, vol. 21, no. 7, pp. 16951703, 2002.

[18] A. Miranda-Vizuete, J. Ljung, A. E. Damdimopoulos et al., "Characterization of sptrx, a novel member of the thioredoxin family specifically expressed in human spermatozoa," Journal of Biological Chemistry, vol. 276, no. 34, pp. 3156731574, 2001.

[19] H. Nakamura, K. Nakamura, and J. Yodoi, "Redox regulation of cellular activation," Annual Review of Immunology, vol. 15, pp. 351-369, 1997.

[20] H. Nakamura, M. Matsuda, K. Furuke et al., "Adult T cell leukemia-derived factor/human thioredoxin protects endothelial F-2 cell injury caused by activated neutrophils or hydrogen peroxide," Immunology Letters, vol. 42, no. 1-2, pp. 75-80, 1994.

[21] W. L. Trigona, I. K. Mullarky, Y. Cao, and L. M. Sordillo, "Thioredoxin reductase regulates the induction of haem oxygenase-1 expression in aortic endothelial cells," Biochemical Journal, vol. 394, no. 1, pp. 207-216, 2006.

[22] K. C. Das, Y. Lewis-Molock, and C. W. White, "Elevation of manganese superoxide dismutase gene expression by thioredoxin," American Journal of Respiratory Cell and Molecular Biology, vol. 17, no. 6, pp. 713-726, 1997.

[23] J. Zhang, Y. D. Li, J. M. Patel, and E. R. Block, “Thioredoxin overexpressin prevents NO-induced reduction of NO synthase activity in lung endothelial cells," American Journal of Physiology, Lung Cellular and Molecular Physiology, vol. 275, no. 2, pp. L288-L293, 1998.

[24] L. E. Shao, T. Tanaka, R. Gribi, and J. Yu, "Thioredoxinrelated regulation of NO/NOS activities," Annals of the New York Academy of Sciences, vol. 962, pp. 140-150, 2002.

[25] J. Haendeler, J. Hoffmann, A. M. Zeiher, and S. Dimmeler, "Antioxidant effects of statins via S-nitrosylation and activation of thioredoxin in endothelial cells: a novel vasculoprotective function of statins," Circulation, vol. 110, no. 7, pp. 856-861, 2004.

[26] E. Junn, S. H. Han, J. Y. Im et al., "Vitamin D3 up-regulated protein 1 mediates oxidative stress via suppressing the thioredoxin function," Journal of Immunology, vol. 164, no. 12, pp. 6287-6295, 2000.

[27] M. Matsui, M. Oshima, H. Oshima et al., "Early embryonic lethality caused by targeted disruption of the mouse thioredoxin gene," Developmental Biology, vol. 178, no. 1, pp. 179$185,1996$.

[28] T. Umekawa, T. Sugiyama, T. Kihira et al., "Overexpression of thioredoxin-1 reduces oxidative stress in the placenta of transgenic mice and promotes fetal growth via glucose metabolism," Endocrinology, vol. 149, no. 8, pp. 3980-3988, 2008.

[29] Y. Kamimoto, T. Sugiyama, T. Kihira et al., "Transgenic mice overproducing human thioredoxin-1, an antioxidative and anti-apoptotic protein, prevents diabetic embryopathy," Diabetologia, vol. 53, no. 9, pp. 2046-2055, 2010.

[30] Y. Hamada, H. Fujii, R. Kitazawa, J. Yodoi, S. Kitazawa, and M. Fukagawa, "Thioredoxin-1 overexpression in transgenic 
mice attenuates streptozotocin-induced diabetic osteopenia: a novel role of oxidative stress and therapeutic implications," Bone, vol. 44, no. 5, pp. 936-941, 2009.

[31] M. Kaimul Ahsan, H. Nakamura, M. Tanito, K. Yamada, H. Utsumi, and J. Yodoi, "Thioredoxin-1 suppresses lung injury and apoptosis induced by diesel exhaust particles (DEP) by scavenging reactive oxygen species and by inhibiting DEPinduced downregulation of Akt," Free Radical Biology and Medicine, vol. 39, no. 12, pp. 1549-1559, 2005.

[32] F. Zhou, M. Gomi, M. Fujimoto et al., "Attenuation of neuronal degeneration in thioredoxin-1 overexpressing mice after mild focal ischemia," Brain Research, vol. 1272, pp. 6270, 2009.

[33] Z. A. Wood, E. Schröder, J. R. Harris, and L. B. Poole, "Structure, mechanism and regulation of peroxiredoxins," Trends in Biochemical Sciences, vol. 28, no. 1, pp. 32-40, 2003.

[34] H. Z. Chae, H. J. Kim, S. W. Kang, and S. G. Rhee, "Characterization of three isoforms of mammalian peroxiredoxin that reduce peroxides in the presence of thioredoxin," Diabetes Research and Clinical Practice, vol. 45, no. 2-3, pp. 101-112, 1999.

[35] S. G. Rhee and H. A. Woo, "Multiple functions of peroxiredoxins: peroxidases, sensors and regulators of the intracellular messenger $\mathrm{H}_{2} \mathrm{O}_{2}$, and protein chaperones," Antioxidants and Redox Signaling, vol. 15, no. 3, pp. 781-794, 2011.

[36] A. V. Peskin, F. M. Low, L. N. Paton, G. J. Maghzal, M. B. Hampton, and C. C. Winterbourn, "The high reactivity of peroxiredoxin 2 with $\mathrm{H}_{2} \mathrm{O}_{2}$ is not reflected in its reaction with other oxidants and thiol reagents," Journal of Biological Chemistry, vol. 282, no. 16, pp. 11885-11892, 2007.

[37] P. J. Leavey, C. Gonzalez-Aller, G. Thurman et al., "A $29-\mathrm{kDa}$ protein associated with p67phox expresses both peroxiredoxin and phospholipase A2 activity and enhances superoxide anion production by a cell-free system of NADPH oxidase activity," Journal of Biological Chemistry, vol. 277, no. 47, pp. 45181-45187, 2002.

[38] J. Uwayama, A. Hirayama, T. Yanagawa et al., "Tissue Prx I in the protection against Fe-NTA and the reduction of nitroxyl radicals," Biochemical and Biophysical Research Communications, vol. 339, no. 1, pp. 226-231, 2006.

[39] J. Fang, T. Nakamura, D. H. Cho, Z. Gu, and S. A. Lipton, "Snitrosylation of peroxiredoxin 2 promotes oxidative stressinduced neuronal cell death in Parkinson's disease," Proceedings of the National Academy of Sciences of the United States of America, vol. 104, no. 47, pp. 18742-18747, 2007.

[40] H. Z. Chae, H. Oubrahim, J. W. Park, S. G. Rhee, and P. B. Chock, "Protein glutathionylation in the regulation of peroxiredoxins: a family of thiol-specific peroxidases that function as antioxidants, molecular chaperones, and signal modulators," Antioxidants \& Redox Signaling, vol. 16, no. 6, pp. 506-523, 2012.

[41] K. S. Yang, S. W. Kang, H. A. Woo et al., "Inactivation of human peroxiredoxin I during catalysis as the result of the oxidation of the catalytic site cysteine to cysteine-sulfinic acid," Journal of Biological Chemistry, vol. 277, no. 41, pp. 3802938036, 2002.

[42] S. Barranco-Medina, J. J. Lázaro, and K. J. Dietz, "The oligomeric conformation of peroxiredoxins links redox state to function," FEBS Letters, vol. 583, no. 12, pp. 1809-1816, 2009.

[43] J. C. Lim, H. I. Choi, Y. S. Park et al., "Irreversible oxidation of the active-site cysteine of peroxiredoxin to cysteine sulfonic acid for enhanced molecular chaperone activity," Journal of Biological Chemistry, vol. 283, no. 43, pp. 28873-28880, 2008.
[44] S. G. Rhee, W. Jeong, T. S. Chang, and H. A. Woo, "Sulfiredoxin, the cysteine sulfinic acid reductase specific to 2Cys peroxiredoxin: its discovery, mechanism of action, and biological significance," Kidney international. Supplement, no. 106, pp. S3-S8, 2007.

[45] C. A. Neumann, D. S. Krause, C. V. Carman et al., "Essential role for the peroxiredoxin Prdx1 in erythrocyte antioxidant defence and tumour suppression," Nature, vol. 424, no. 6948, pp. 561-565, 2003.

[46] T. H. Lee, S. U. Kim, S. L. Yu et al., "Peroxiredoxin II is essential for sustaining life span of erythrocytes in mice," Blood, vol. 101, no. 12, pp. 5033-5038, 2003.

[47] S. Agrawal-Singh, F. Isken, K. Agelopoulos et al., "Genomewide analysis of histone $\mathrm{H} 3$ acetylation patterns in AML identifies PRDX2 as an epigenetically silenced tumor suppressor gene," Blood, vol. 119, no. 10, pp. 2346-2357, 2012.

[48] L. Li, W. Shoji, H. Takano et al., "Increased susceptibility of MER5 (peroxiredoxin III) knockout mice to LPS-induced oxidative stress," Biochemical and Biophysical Research Communications, vol. 355, no. 3, pp. 715-721, 2007.

[49] A. G. Cox, C. C. Winterbourn, and M. B. Hampton, "Mitochondrial peroxiredoxin involvement in antioxidant defence and redox signalling," Biochemical Journal, vol. 425, no. 2, pp. 313-325, 2010.

[50] T. S. Chang, C. S. Cho, S. Park, S. Yu, W. K. Sang, and G. R. Sue, "Peroxiredoxin III, a mitochondrion-specific peroxidase, regulates apoptotic signaling by mitochondria," Journal of Biological Chemistry, vol. 279, no. 40, pp. 41975-41984, 2004.

[51] J. Y. Huh, Y. Kim, J. Jeong et al., "Peroxiredoxin 3 is a key molecule regulating adipocyte oxidative stress, mitochondrial biogenesis, and adipokine expression," Antioxidants \& Redox Signaling, vol. 16, no. 3, pp. 229-243, 2012.

[52] Y. Iuchi, F. Okada, S. Tsunoda et al., "Peroxiredoxin 4 knockout results in elevated spermatogenic cell death via oxidative stress," Biochemical Journal, vol. 419, no. 1, pp. 149-158, 2009.

[53] Y. Zhou, K. H. Kok, A. C. S. Chun et al., "Mouse peroxiredoxin $\mathrm{V}$ is a thioredoxin peroxidase that inhibits p53induced apoptosis," Biochemical and Biophysical Research Communications, vol. 268, no. 3, pp. 921-927, 2000.

[54] N. Nagy, G. Malik, A. B. Fisher, and D. K. Das, "Targeted disruption of peroxiredoxin 6 gene renders the heart vulnerable to ischemia-reperfusion injury," American Journal of Physiology, Heart and Circulatory Physiology, vol. 291, no. 6, pp. H2636-H2640, 2006.

[55] Y. Manevich and A. B. Fisher, "Peroxiredoxin 6, a 1-Cys peroxiredoxin, functions in antioxidant defense and lung phospholipid metabolism," Free Radical Biology and Medicine, vol. 38, no. 11, pp. 1422-1432, 2005.

[56] L. C. P. Azevedo, M. A. Pedro, and F. R. M. Laurindo, "Circulating microparticles as therapeutic targets in cardiovascular diseases," Recent Patents on Cardiovascular Drug Discovery, vol. 2, no. 1, pp. 41-51, 2007.

[57] S. I. Buschow, B. W. M. Van Balkom, M. Aalberts, A. J. R. Heck, M. Wauben, and W. Stoorvogel, "MHC class IIassociated proteins in B-cell exosomes and potential functional implications for exosome biogenesis," Immunology and Cell Biology, vol. 88, no. 8, pp. 851-856, 2010.

[58] J. L. Welton, S. Khanna, P. J. Giles et al., "Proteomics analysis of bladder cancer exosomes," Molecular and Cellular Proteomics, vol. 9, no. 6, pp. 1324-1338, 2010.

[59] D. S. Choi, J. M. Lee, W. P. Gun et al., "Proteomic analysis of microvesicles derived from human colorectal cancer cells," 
Journal of Proteome Research, vol. 6, no. 12, pp. 4646-4655, 2007.

[60] P. A. Gonzales, T. Pisitkun, J. D. Hoffert et al., "Large-scale proteomics and phosphoproteomics of urinary exosomes," Journal of the American Society of Nephrology, vol. 20, no. 2, pp. 363-379, 2009.

[61] A. J. Dessein, H. L. Lenzi, and J. C. Bina, "Modulation of eosinophil cytotoxicity by blood mononuclear cells from healthy subjects and patients with chronic schistosomiasis mansoni," Cellular Immunology, vol. 85, no. 1, pp. 100-113, 1984.

[62] K. Pekkari, R. Gurunath, E. S. J. Arner, and A. Holmgren, "Truncated thioredoxin is a mitogenic cytokine for resting human peripheral blood mononuclear cells and is present in human plasma," Journal of Biological Chemistry, vol. 275, no. 48, pp. 37474-37480, 2000.

[63] K. Pekkari, J. Avila-Carino, A. Bengtsson, R. Gurunath, A. Scheynius, and A. Holmgren, "Truncated thioredoxin. (Trx80) induces production of interleukin-12 and enhances CD14 expression in human monocytes," Blood, vol. 97, no. 10, pp. 3184-3190, 2001.

[64] N. Kondo, Y. Ishii, Y. W. Kwon et al., "Redox-sensing release of human thioredoxin from $t$ lymphocytes with negative feedback loops," Journal of Immunology, vol. 172, no. 1, pp. 442-448, 2004.

[65] T. Jikimoto, Y. Nishikubo, M. Koshiba et al., "Thioredoxin as a biomarker for oxidative stress in patients with rheumatoid arthritis," Molecular Immunology, vol. 38, no. 10, pp. 765$772,2002$.

[66] S. K. Leaver, N. S. MacCallum, V. Pingle et al., "Increased plasma thioredoxin levels in patients with sepsis: positive association with macrophage migration inhibitory factor," Intensive Care Medicine, vol. 36, no. 2, pp. 336-341, 2010.

[67] A. L. Mowbray, D. H. Kang, G. R. Sue, W. K. Sang, and H. Jo, "Laminar shear stress up-regulates peroxiredoxins (PRX) in endothelial cells: PRX 1 as a mechanosensitive antioxidant," Journal of Biological Chemistry, vol. 283, no. 3, pp. 1622 1627, 2008.

[68] C. Lehel, Z. Oláh, G. Petrovics, G. Jakab, and W. B. Anderson, "Influence of various domains of protein kinase $\mathrm{C} \in$ on its PMA-induced translocation from the golgi to the plasma membrane," Biochemical and Biophysical Research Communications, vol. 223, no. 1, pp. 98-103, 1996.

[69] D. R. Ambruso, M. A. Ellison, G. W. Thurman, and T. L. Leto, "Peroxiredoxin 6 translocates to the plasma membrane during neutrophil activation and is required for optimal NADPH oxidase activity," Biochimica et Biophysica Acta, vol. 1823, no. 2, pp. 306-315, 2012.

[70] J. W. Chang, S. H. Lee, Y. Lu, and Y. J. Yoo, “Transforming growth factor- $\beta 1$ induces the non-classical secretion of peroxiredoxin-I in A549 cells," Biochemical and Biophysical Research Communications, vol. 345, no. 1, pp. 118-123, 2006.

[71] W. C. Jong, H. L. Seung, Y. J. Ju et al., "Peroxiredoxin-I is an autoimmunogenic tumor antigen in non-small cell lung cancer," FEBS Letters, vol. 579, no. 13, pp. 2873-2877, 2005.

[72] S. Yoshida, T. Katoh, T. Tetsuka, K. Uno, N. Matsui, and T. Okamoto, "Involvement of thioredoxin in rheumatoid arthritis: its costimulatory roles in the TNF- $\alpha$-induced production of IL-6 and IL-8 from cultured synovial fibroblasts," Journal of Immunology, vol. 163, no. 1, pp. 351-358, 1999.

[73] C. Hunter-Lavin, E. L. Davies, M. M. F. V. G. Bacelar, M. J. Marshall, S. M. Andrew, and J. H. H. Williams, "Hsp70 release from peripheral blood mononuclear cells,"
Biochemical and Biophysical Research Communications, vol. 324, no. 2, pp. 511-517, 2004.

[74] A. Asea, M. Rehli, E. Kabingu et al., "Novel signal transduction pathway utilized by extracellular HSP70. Role of toll-like receptor (TLR) 2 and TLR4," Journal of Biological Chemistry, vol. 277, no. 17, pp. 15028-15034, 2002.

[75] M. T. Lotze, H. J. Zeh, A. Rubartelli et al., "The grateful dead: damage-associated molecular pattern molecules and reduction/oxidation regulate immunity," Immunological Reviews, vol. 220, no. 1, pp. 60-81, 2007.

[76] P. Westermann, M. Knoblich, O. Maier, C. Lindschau, and H. Haller, "Protein kinase C bound to the Golgi apparatus supports the formation of constitutive transport vesicles," Biochemical Journal, vol. 320, no. 2, pp. 651-658, 1996.

[77] S. Staubach, H. Razawi, and F. G. Hanisch, "Proteomics of MUC1-containing lipid rafts from plasma membranes and exosomes of human breast carcinoma cells MCF-7," Proteomics, vol. 9, no. 10, pp. 2820-2835, 2009.

[78] C. Admyre, S. M. Johansson, K. R. Qazi et al., "Exosomes with immune modulatory features are present in human breast milk," Journal of Immunology, vol. 179, no. 3, pp. 19691978, 2007.

[79] M. Gonzalez-Begne, B. Lu, X. Han et al., "Proteomic analysis of human parotid gland exosomes by multidimensional protein identification technology (MudPIT)," Journal of Proteome Research, vol. 8, no. 3, pp. 1304-1314, 2009.

[80] D. Harrison, K. K. Griendling, U. Landmesser, B. Hornig, and H. Drexler, "Role of oxidative stress in atherosclerosis," American Journal of Cardiology, vol. 91, no. 3, pp. A7-A11, 2003.

[81] Y. Lu and L. M. Wahl, "Oxidative stress augments the production of matrix metalloproteinase-1, cyclooxygenase2, and prostaglandin E2 through enhancement of NF$\kappa \mathrm{B}$ activity in lipopolysaccharide-activated human primary monocytes," Journal of Immunology, vol. 175, no. 8, pp. 54235429, 2005.

[82] J. Blumberg, "Use of biomarkers of oxidative stress in research studies," Journal of Nutrition, vol. 134, no. 11, pp. 3188S-3189S, 2004.

[83] R. Virmani, A. P. Burke, A. Farb, and F. D. Kolodgie, "Pathology of the Vulnerable Plaque," Journal of the American College of Cardiology, vol. 47, no. 8, supplement, pp. C13C18, 2006.

[84] H. Jo, H. Song, and A. Mowbray, "Role of NADPH oxidases in disturbed flow- and BMP4-induced inflammation and atherosclerosis," Antioxidants and Redox Signaling, vol. 8, no. 9-10, pp. 1609-1619, 2006.

[85] A. Qu, C. Jiang, M. Xu et al., "PGC- $1 \alpha$ attenuates neointimal formation via inhibition of vascular smooth muscle cell migration in the injured rat carotid artery," American Journal of Physiology, Cell Physiology, vol. 297, no. 3, pp. C645-C653, 2009.

[86] D. A. Popowich, A. K. Vavra, C. P. Walsh et al., "Regulation of reactive oxygen species by $\mathrm{p} 53$ : implications for nitric oxidemediated apoptosis," American Journal of Physiology, Heart and Circulatory Physiology, vol. 298, no. 6, pp. H2192-H2200, 2010.

[87] B. Sahaf and A. Rosén, "Secretion of $10-\mathrm{kDa}$ and $12-\mathrm{kDa}$ thioredoxin species from blood monocytes and transformed leukocytes," Antioxidants and Redox Signaling, vol. 2, no. 4, pp. 717-726, 2000.

[88] A. Hess, N. Wijayanti, A. P. Neuschäfer-Rube, N. Katz, T. Kietzmann, and S. Immenschuh, "Phorbol ester-dependent activation of peroxiredoxin i gene expression via a protein 
kinase C, Ras, p38 mitogen-activated protein kinase signaling pathway," Journal of Biological Chemistry, vol. 278, no. 46, pp. 45419-45434, 2003.

[89] M. K. Cha and I. H. Kim, “Thioredoxin-linked peroxidase from human red blood cell: evidence for the existence of thioredoxin and thioredoxin reductase in human red blood cell," Biochemical and Biophysical Research Communications, vol. 217, no. 3, pp. 900-907, 1995.

[90] R. Martinez-Pinna, P. Ramos-Mozo, J. Madrigal-Matute et al., "Identification of peroxiredoxin-1 as a novel biomarker of abdominal aortic aneurysm," Arteriosclerosis, Thrombosis, and Vascular Biology, vol. 31, no. 4, pp. 935-943, 2011.

[91] R. Martinez-Pinna, J. S. Lindholt, L. M. Blanco-Colio et al., "Increased levels of thioredoxin in patients with abdominal aortic aneurysms (AAAs). A potential link of oxidative stress with AAA evolution," Atherosclerosis, vol. 212, no. 1, pp. 333$338,2010$.

[92] M. Okuda, N. Inoue, H. Azumi et al., "Expression of glutaredoxin in human coronary arteries: its potential role in antioxidant protection against atherosclerosis," Arteriosclerosis, Thrombosis, and Vascular Biology, vol. 21, no. 9, pp. 14831487, 2001.

[93] Y. Takagi, Y. Gon, T. Todaka et al., "Expression of thioredoxin is enhanced in atherosclerotic plaques and during neointima formation in rat arteries," Laboratory Investigation, vol. 78, no. 8, pp. 957-966, 1998.

[94] K. Nishihira, A. Yamashita, T. Imamura et al., "Thioredoxin in coronary culprit lesions: possible relationship to oxidative stress and intraplaque hemorrhage," Atherosclerosis, vol. 201, no. 2, pp. 360-367, 2008.

[95] C. Furman, A. K. Rundlöf, G. Larigauderie et al., "Thioredoxin reductase 1 is upregulated in atherosclerotic plaques: specific induction of the promoter in human macrophages by oxidized low-density lipoproteins," Free Radical Biology and Medicine, vol. 37, no. 1, pp. 71-85, 2004.

[96] T. Turoczi, V. W. H. Chang, R. M. Engelman, N. Maulik, Y. S. Ho, and D. K. Das, "Thioredoxin redox signaling in the ischemic heart: an insight with transgenic mice overexpressing Trx1," Journal of Molecular and Cellular Cardiology, vol. 35, no. 6, pp. 695-704, 2003.

[97] S. M. Samuel, M. Thirunavukkarasu, S. V. Penumathsa et al., "Thioredoxin-1 gene therapy enhances angiogenic signaling and reduces ventricular remodeling in infarcted myocardium of diabetic rats," Circulation, vol. 121, no. 10, pp. 1244-1255, 2010.

[98] R. S. Adluri, M. Thirunavukkarasu, L. Zhan et al., "Thioredoxin 1 enhances neovascularization and reduces ventricular remodeling during chronic myocardial infarction: a study using thioredoxin 1 transgenic mice," Journal of Molecular and Cellular Cardiology, vol. 50, no. 1, pp. 239-247, 2011.

[99] M. Yamamoto, G. Yang, C. Hong et al., "Inhibition of endogenous thioredoxin in the heart increases oxidative stress and cardiac hypertrophy," Journal of Clinical Investigation, vol. 112, no. 9, pp. 1395-1406, 2003.

[100] Y. Yang, T. Ago, P. Zhai, M. Abdellatif, and J. Sadoshima, "Thioredoxin 1 negatively regulates angiotensin II-Induced cardiac hypertrophy through upregulation of miR-98/let-7," Circulation Research, vol. 108, no. 3, pp. 305-313, 2011.

[101] J. Yoshioka, P. C. Schulze, M. Cupesi et al., "Thioredoxininteracting protein controls cardiac hypertrophy through regulation of thioredoxin activity," Circulation, vol. 109, no. 21, pp. 2581-2586, 2004.
[102] C. J. Lowenstein, "Exogenous thioredoxin reduces inflammation in autoimmune myocarditis," Circulation, vol. 110, no. 10, pp. 1178-1179, 2004.

[103] L. Billiet, C. Furman, G. Larigauderie et al., "Extracellular human thioredoxin-1 inhibits lipopolysaccharide-induced interleukin- $1 \beta$ expression in human monocyte-derived macrophages," Journal of Biological Chemistry, vol. 280, no. 48, pp. 40310-40318, 2005.

[104] W. Liu, H. Nakamura, K. Shioji et al., "Thioredoxin-1 ameliorates myosin-induced autoimmune myocarditis by suppressing chemokine expressions and leukocyte chemotaxis in mice," Circulation, vol. 110, no. 10, pp. 1276-1283, 2004.

[105] M. Aota, K. Matsuda, N. Isowa, H. Wada, J. Yodoi, and T. Ban, "Protection against reperfusion-induced arrhythmias by human thioredoxin," Journal of Cardiovascular Pharmacology, vol. 27, no. 5, pp. 727-732, 1996.

[106] I. Hattori, Y. Takagi, H. Nakamura et al., "Intravenous administration of thioredoxin decreases brain damage following transient focal cerebral ischemia in mice," Antioxidants and Redox Signaling, vol. 6, no. 1, pp. 81-87, 2004.

[107] S. Koneru, S. V. Penumathsa, M. Thirunavukkarasu, L. Zhan, and N. Maulik, "Thioredoxin-1 gene delivery induces heme oxygenase-1 mediated myocardial preservation after chronic infarction in hypertensive rats," American Journal of Hypertension, vol. 22, no. 2, pp. 183-190, 2009.

[108] S. Miyamoto, T. Sakamoto, H. Soejima et al., "Plasma thioredoxin levels and platelet aggregability in patients with acute myocardial infarction," American Heart Journal, vol. 146, no. 3, pp. 465-471, 2003.

[109] J. Hokamaki, H. Kawano, H. Soejima et al., "Plasma thioredoxin levels in patients with unstable angina," International Journal of Cardiology, vol. 99, no. 2, pp. 225-231, 2005.

[110] Y. Wu, L. Yang, and L. Zhong, "Decreased serum levels of thioredoxin in patients with coronary artery disease plus hyperhomocysteinemia is strongly associated with the disease severity," Atherosclerosis, vol. 212, no. 1, pp. 351-355, 2010.

[111] C. M. Wahlgren and K. Pekkari, "Elevated thioredoxin after angioplasty in peripheral arterial disease," European Journal of Vascular and Endovascular Surgery, vol. 29, no. 3, pp. 281286, 2005.

[112] N. Wijayanti, S. Naidu, T. Kietzmann, and S. Immenschuh, "Inhibition of phorbol ester-dependent peroxiredoxin I gene activation by lipopolysaccharide via phosphorylation of RelA/p65 at serine 276 in monocytes," Free Radical Biology and Medicine, vol. 44, no. 4, pp. 699-710, 2008.

[113] M. H. Choi, I. K. Lee, G. W. Kim et al., "Regulation of PDGF signalling and vascular remodelling by peroxiredoxin II," Nature, vol. 435, no. 7040, pp. 347-353, 2005.

[114] S. G. Rhee, S. W. Kang, W. Jeong, T. S. Chang, K. S. Yang, and H. A. Woo, "Intracellular messenger function of hydrogen peroxide and its regulation by peroxiredoxins," Current Opinion in Cell Biology, vol. 17, no. 2, pp. 183-189, 2005.

[115] K. Ihida-Stansbury, D. M. McKean, S. A. Gebb et al., "Regulation and functions of the paired-related homeobox gene PRX1 in pulmonary vascular development and disease," Chest, vol. 128, no. 6, supplement, p. S591, 2005.

[116] J. Kisucka, A. K. Chauhan, I. S. Patten et al., "Peroxiredoxin 1 prevents excessive endothelial activation and early atherosclerosis," Circulation Research, vol. 103, no. 6, pp. 598605, 2008. 
[117] J.-G. Park, J.-Y. Yoo, S.-J. Jeong et al., "Peroxiredoxin 2 deficiency exacerbates atherosclerosis in apolipoprotein Edeficient mice," Circulation Research, vol. 109, no. 7, pp. 739749, 2011.

[118] S. W. Kang, S. G. Rhee, T. S. Chang, W. Jeong, and M. H. Choi, "2-Cys peroxiredoxin function in intracellular signal transduction: therapeutic implications," Trends in Molecular Medicine, vol. 11, no. 12, pp. 571-578, 2005.

[119] W. Li, M. Febbraio, S. P. Reddy, D. Y. Yu, M. Yamamoto, and R. L. Silverstein, "CD36 participates in a signaling pathway that regulates ROS formation in murine VSMCs," Journal of Clinical Investigation, vol. 120, no. 11, pp. 3996-4006, 2010.

[120] S. Urbonavicius, J. S. Lindholt, H. Vorum, G. Urbonaviciene, E. W. Henneberg, and B. Honoré, "Proteomic identification of differentially expressed proteins in aortic wall of patients with ruptured and nonruptured abdominal aortic aneurysms," Journal of Vascular Surgery, vol. 49, no. 2, pp. 455-463, 2009.

[121] F. J. Miller Jr., W. J. Sharp, X. Fang, L. W. Oberley, T. D. Oberley, and N. L. Weintraub, "Oxidative stress in human abdominal aortic aneurysms: a potential mediator of aneurysmal remodeling," Arteriosclerosis, Thrombosis, and Vascular Biology, vol. 22, no. 4, pp. 560-565, 2002.

[122] S. Matsushima, T. Ide, M. Yamato et al., "Overexpression of mitochondrial peroxiredoxin-3 prevents left ventricular remodeling and failure after myocardial infarction in mice," Circulation, vol. 113, no. 14, pp. 1779-1786, 2006. 


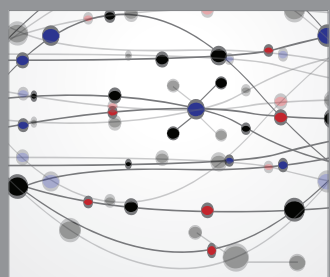

The Scientific World Journal
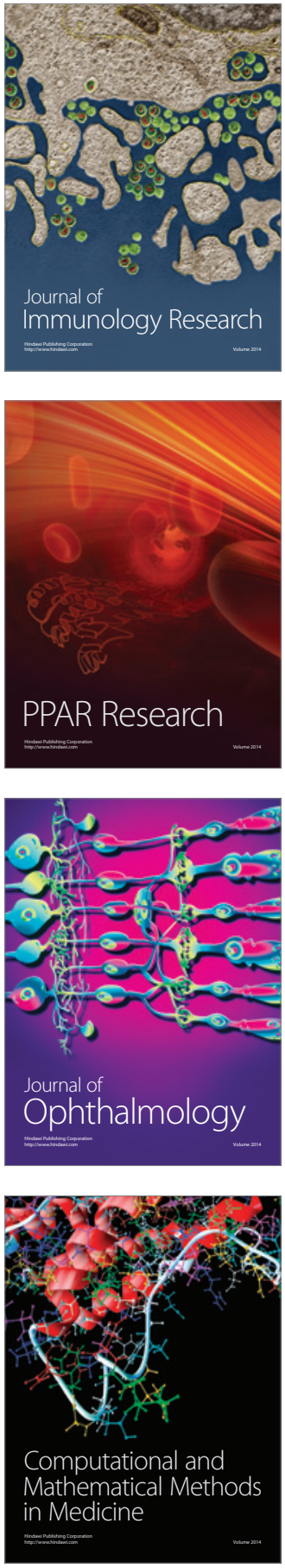

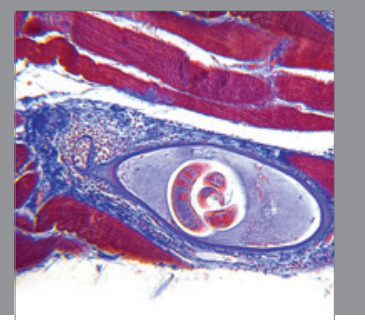

Gastroenterology

Research and Practice
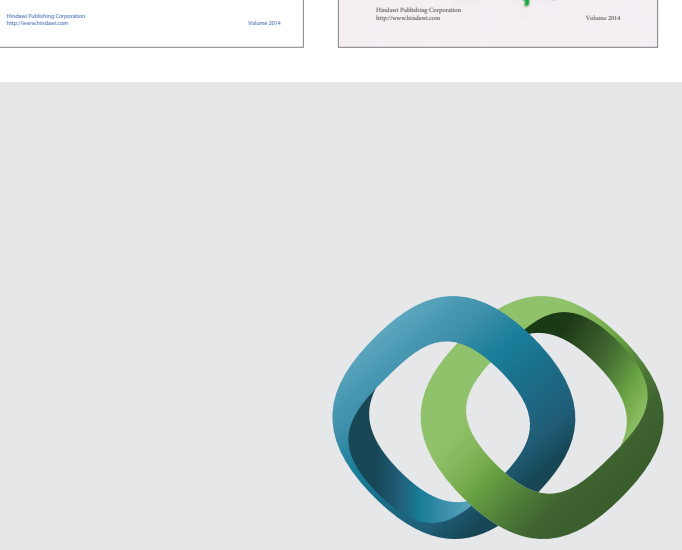

\section{Hindawi}

Submit your manuscripts at

http://www.hindawi.com
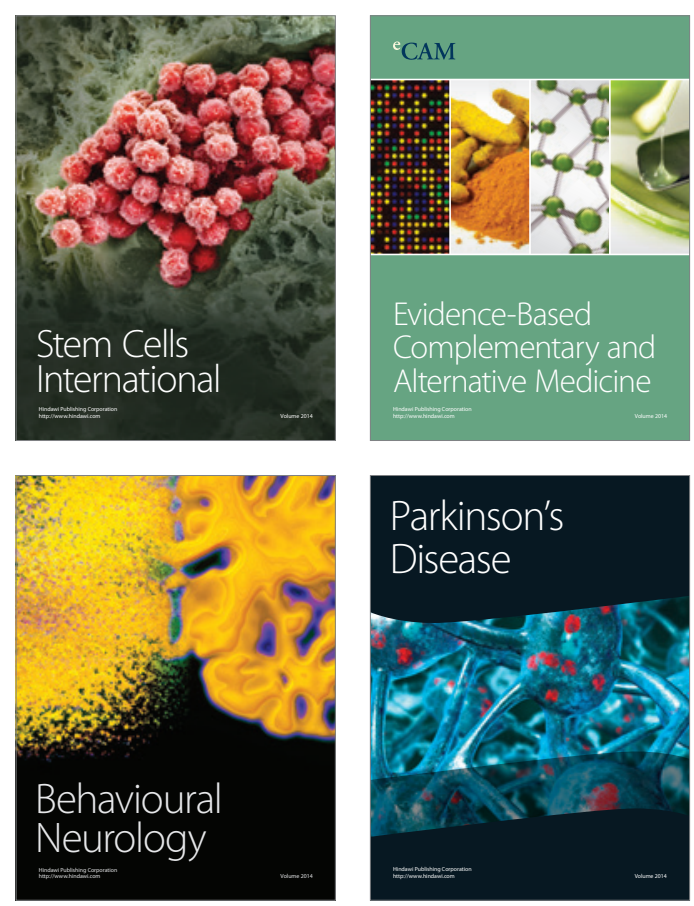

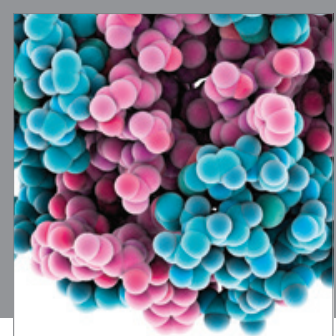

Journal of
Diabetes Research

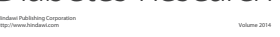

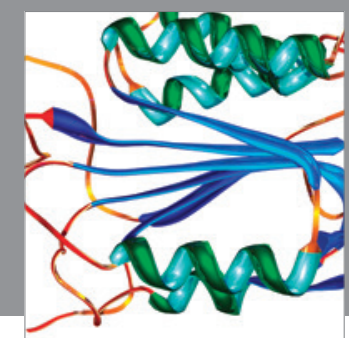

Disease Markers
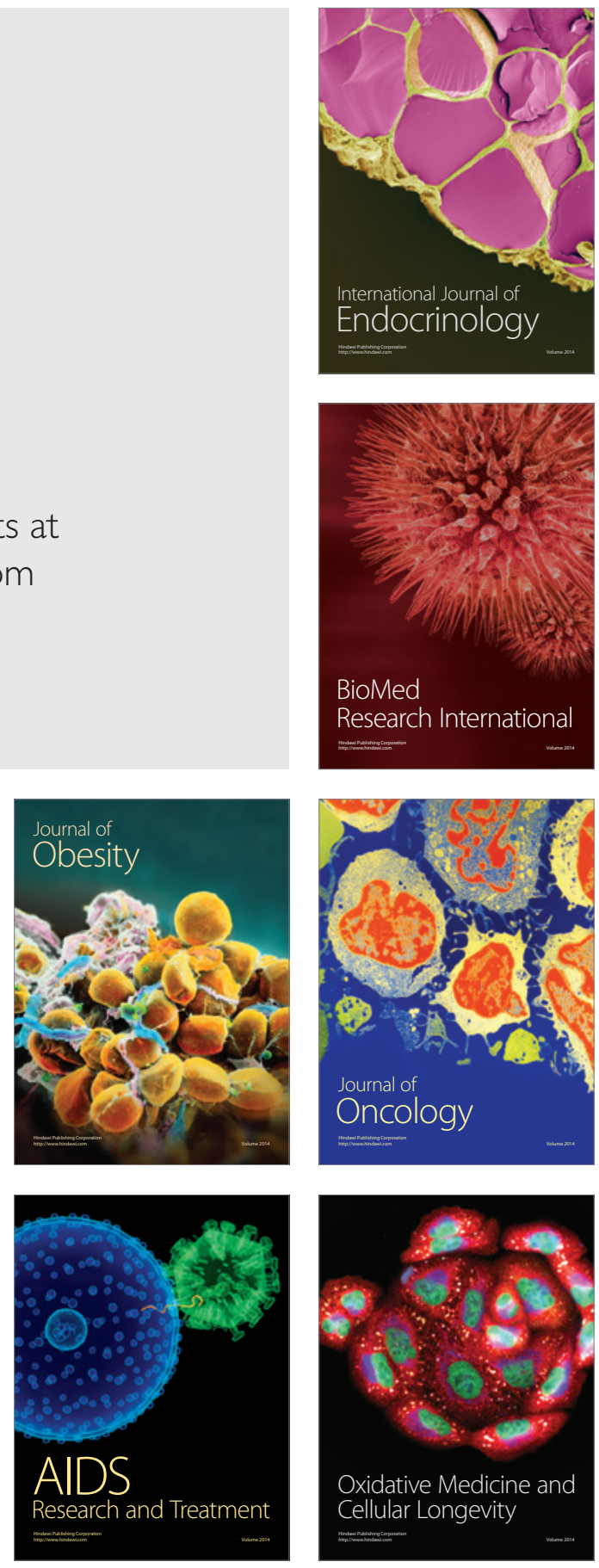